\title{
THE NOVEMBER MEETING IN MINNEAPOLIS
}

The seven hundred eighth meeting of the American Mathematical Society was held at the University of Minnesota, Minneapolis, Minnesota, on Saturday, November 3, 1973. There were 181 registrants, including 154 members of the Society.

By invitation of the Committee to Select Hour Speakers for Western Sectional Meetings there were two one-hour addresses. Professor Frank A. Raymond of the University of Michigan spoke on Deforming self-homotopy equivalences to homeomorphisms in certain aspherical manifolds; he was introduced by Professor William F. Pohl. Professor Jean-Pierre Kahane of the University of Paris addressed the Society on the subject "Hereditary properties in metric projections;" the presiding officer at his lecture was Professor Donald L. Burkholder. Professor Kahane was a last-minute replacement for Professor Charles L. Fefferman, who was originally scheduled to speak but was obliged to withdraw because of illness.

By invitation of the same committee there were four special sessions of selected twenty-minute papers. Professors Albert Marden of the University of Minnesota and the University of Maryland and Edgar Reich of the University of Minnesota arranged a special session on Complex Analysis; the speakers were Albert Baernstein II, David Drasin, Stephen D. Fisher, Frederick W. Gehring, Maurice H. Heins, Joseph B. Miles, Richard H. Rochberg, and Walter Rudin. Professors Robert F. Craggs of the University of Illinois and Peter P. Orlik of the University of Wisconsin arranged a special session on Compact Transformation Groups; the speakers were Robert F. Craggs, Louis H. Kauffman, Chung Nim Lee, Peter P. Orlik, Richard C. Randell, Melvin Rothenberg, Reinhard E. Schultz, Philip D. Wagreich, and Arthur G. Wasserman. Professors Robert W. Carroll of the University of Illinois and Walter Littman of the University of Minnesota arranged a special session on Partial Differential Equations; the speakers were Neal R. Amundson, M. S. Baouendi, Richard W. Beals, Robert W. Carroll, John M. Chadam, Robert Gulliver, Jeff E. Lewis, Paul H. Rabinowitz, and Joel A. Smoller. Professors Robert Ellis and Harvey B. Keynes of the University of Minnesota arranged a special session on Topological Dynamics; the speakers were Shmuel Glasner, Nelson G. Markley, and Karl E. Petersen.

In addition there was a general session of ten contributed ten-minute papers chaired by Professors J. Ian Richards and David A. Storvick, a session of six contributed tenminute papers on topological dynamics chaired by Professor Harvey B. Keynes, and an informal problem session on topological dynamics moderated by Professor Leonard D. Shapiro.

URBANA, ILLINOIS

Paul T. Bateman Associate Secretary 